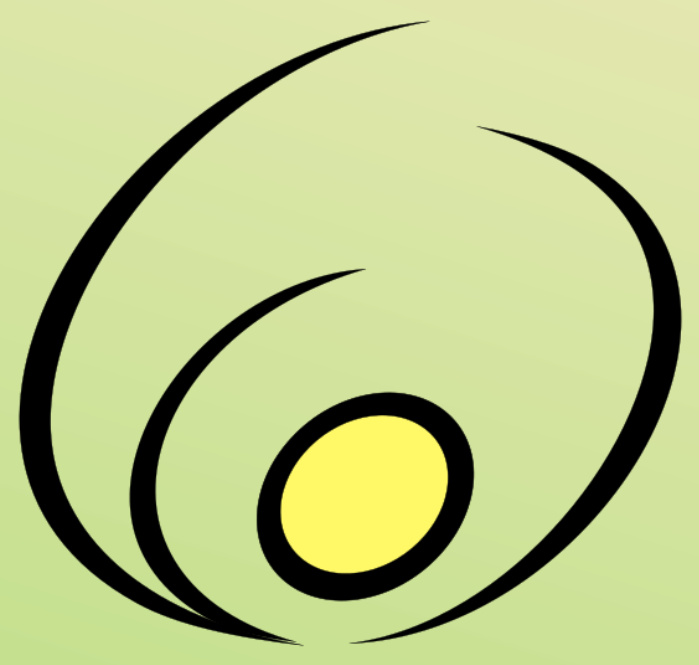

Fórum de

\section{Pró-Reitores}

de Extensão

das Instituições

Públicas de

Educação Superior

Brasileiras
Open access $\oint$ free available online

Revista Brasileira de Extensão Universitária

v. 8 , n. 1 , p. 5 jan./abr. 2017

e-ISSN 2358-0399

DOI: http://dx.doi.org/10.24317/2358-0399.2017v8i1p5

\title{
Editorial - os três primeiros anos de publicação eletrônica da RBEU
}

Com o número 1 do Volume 8, iniciamos uma nova etapa da Revista Brasileira de Extensão Universitária (RBEU), agora quadrimestral.

Cumpre apresentar alguns números sobre os três anos de trabalho da RBEU na forma eletrônica (2014-2016). Foram três volumes (um por ano), com dois números cada um. Ao todo foram publicados 39 trabalhos, (37 artigos e duas entrevistas). Observa-se uma evolução rápida do número de elementos publicados por ano (Figura 1).

Em 2016, foram 78 trabalhos submetidos. Destes, 49 foram arquivados (rejeitados ou sem resposta por parte dos autores após avaliação), 17 foram publicados e 14 ainda estão em avaliação. $\mathrm{O}$ tempo médio entre a submissão e o aceite, no caso dos artigos publicados no número 2 do volume $7(\mathrm{n}=11)$ foi de 5,5 meses. A maior dificuldade para reduzir este tempo está relacionada à dificuldade de obter pareceres, em número mínimo de dois, e que sejam convergentes em seu veredicto (no caso de divergência, solicitamos um terceiro parecer). Por outro lado, a publicação antecipada online reduz o tempo de publicação, aumentando a visibilidade dos trabalhos, que não precisam esperar pelo fechamento de cada edição. 
Os trabalhos publicados nestes três anos (39) apresentam nove citações no Google Acadêmico (GA), Entretanto, verificamos outras cinco citações após uma busca mais profunda, que não aparecem diretamente logo abaixo de cada artigo (busca automática), em função da falta de metadados, não informados adequadamente por parte da fonte publicadora.

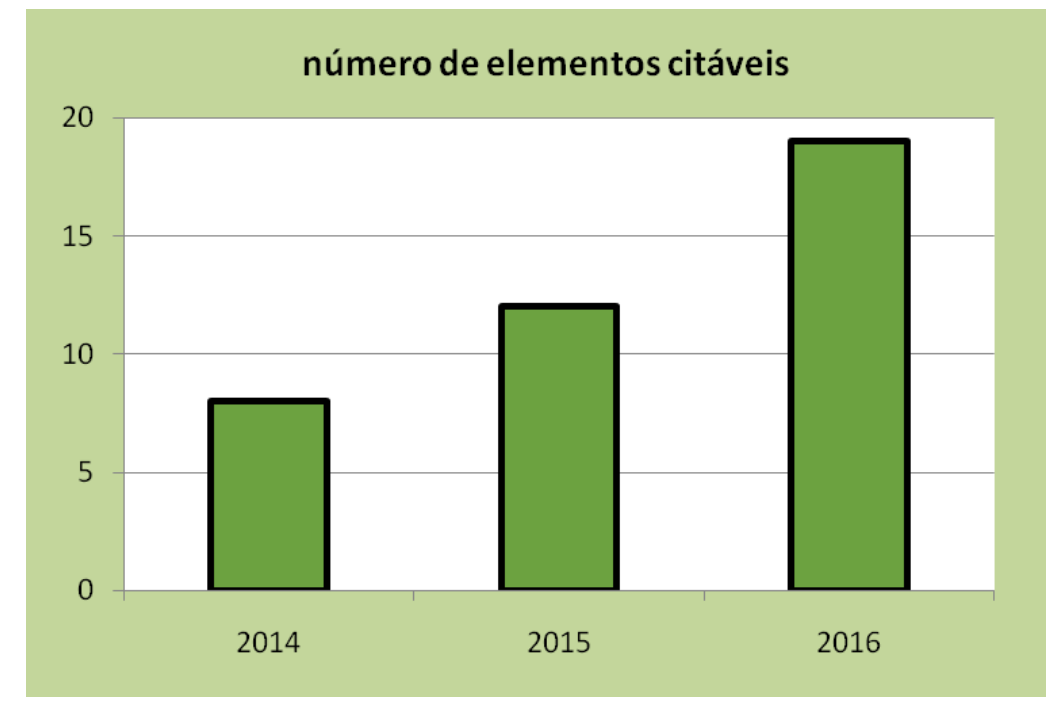

Figura 1. Número de elementos citáveis (artigos e entrevistas) publicados na Revista Brasileira de Extensão Universitária (RBEU) entre 2014 e 2016.

Quatro destas nove citações foram feitas entre 2015 e 2016 e são referentes a trabalhos publicados no ano de 2014, o que gera uma intensidade de citação (Ic) ${ }^{1}$ relativamente elevada (Quadro 1).

Se calculássemos um fator de impacto ${ }^{2}$ com base nas citações do Engenho de Busca (GA) citado acima, teríamos um índice de 0,30 (se levássemos em conta todas as citações, obtidas em uma busca mais aprofundada, este índice seria de 0,50).

Quadro 1. Número de elementos publicáveis veiculados, número de citações e índice de impacto calculado a partir do Google Acadêmico (GA) 2 .

\begin{tabular}{|lcccc|}
\hline & RBEU & Revista A & Revista B & Revista C \\
\hline $\begin{array}{l}\text { A.Número de elementos citáveis } \\
\text { publicados em 2014 }\end{array}$ & 8 & 45 & 30 & 28 \\
\hline $\begin{array}{l}\text { B. Número de citações de 'A' } \\
\text { (acima) em 2015-2016 }\end{array}$ & 4 & 7 & 13 & 9 \\
\hline \begin{tabular}{l} 
Intensidade de Citação (Ic = B/A) \\
\hline Fator de Impacto $\mathrm{F}_{\mathrm{GA}}(2016)^{2}$
\end{tabular} & 0,50 & 0,18 & 0,45 & 0,32 \\
\hline Total de citações $(2014-2016)$ & 0,300 & 0,128 & 0,271 & 0,167 \\
\hline
\end{tabular}

* número entre parêntesis se refere a uma busca mais profunda, não automática, no Google Acadêmico. 
Estes índices apresentados pela RBEU não podem ser considerados baixos, em comparação com outras revistas brasileiras de extensão universitária de grande conceito (Quadro 1) ou mesmo com outras revistas de perfil similar ${ }^{3}$.

Evidentemente, os trabalhos nas Revistas de Extensão poderiam ser mais citados, especialmente considerando que temos cerca de 30 revistas acadêmicas revisadas por pares dedicadas à extensão universitária no Brasil ${ }^{4}$. Na RBEU, estamos estimulando este diálogo, recomendando uma revisão bibliográfica nestes veículos, com um link para aquelas que possuem versão eletrônica.

Esperamos, com estas inovações, contribuir cada vez mais para o debate acadêmico da Extensão Universitária no Brasil.

Por último, mas não menos importante, é dever manifestar nossos sinceros agradecimentos ao trabalho voluntário dos pareceristas, indispensável para garantir a qualidade do conteúdo publicado. Aos autores, agradecemos a confiança em nosso projeto.

\section{Boa leitura!}

Geraldo Ceni Coelho

Editor

\section{Notas:}

1. O Ic (intensidade de citação) é o número médio de citações de artigos de um periódico, publicados em um determinado ano, feitas nos dois anos subseqüentes.

2. O fator de impacto é calculado segundo a razão $X / Y$, na qual $X$ é igual ao número de citações em um determinado ano, de artigos de um periódico publicados nos dois anos anteriores, e $Y$ é o número total de elementos publicados nestes dois anos anteriores. O fator de impacto de 2016 é o número de citações, em 2016, de artigos publicados no periódico em questão em 2014-2015. O fator de impacto é usualmente calculado a partir de bases bibliométricas como o SCImago e JCR; o índice apresentado aqui é uma analogia, embora não usualmente utilizado, até porque existem imprecisões nos dados oferecidos pelo Google Acadêmico (GA), e o fato de que as citações do GA incluem qualquer forma de publicação (dissertações, teses, trabalhos em eventos, artigos em periódicos, e outros meios). Além disso, as citações são subestimadas no GA, visto que muitas revistas não oferecem em sua publicação eletrônica o campo de metadados denominado 'referências'. Por outro lado, não existem revistas brasileiras de extensão universitária indexadas no SCImago e no JCR, o que impede uma comparação através do fator de impacto por estas bases. Em que pesem as limitações, o índice é válido, pressupondo-se que as limitações do GA são sistemáticas, ocorrendo igualmente para todos os periódicos. Sobre este assunto, ver também: DELGADO-LÓPEZCÓZAR, E.; CABEZAS-CLAVIJO, Á. Ranking journals: could Google scholar metrics be an alternative to journal citation reports and Scimago journal rank? Learned Publishing, v. 26, n. 2, p. 101-113, 2013.

3. A Revista Z, tomada como parâmetro de comparação, apresenta um índice Ic de 0,51 (20 citações em 2015-2016 para os 39 elementos citáveis publicados em 2014) e um $\mathrm{F}_{\mathrm{GA}}(2016)=0$,206. A Revista $Z$ apresenta diversas semelhanças importantes com a maioria das revistas de extensão universitária brasileiras, por ser multidisciplinar, sem uma vinculação direta com uma área de conhecimento em específico, não indexada no JCR ou SCImago, com artigos em língua portuguesa, e por usar a plataforma SEER/OJS. Sua classificação Qualis 2015 varia entre A2 e C, nas diferentes áreas.

4. COELhO, G. C. Revistas acadêmicas de extensão universitária no Brasil. Revista Brasileira de Extensão Universitária, v. 5, n. 2, p. 69-75, 2014.

FIRME, S. M.; CORREA, T. P. P.; MIRANDA, A. C. D.; SHINTAKU, M. Revistas de extensão e o acesso aberto ao conhecimento: mapeamento dos periódicos eletrônicos no Brasil. Ágora, v. 26, n. 52, p. 151-178, 2016. 